\title{
Fabrication and Properties of Zinc Composite Coatings for Mitigation of Corrosion in Coastal and Marine Zone
}

\author{
Patricia A.I. Popoola, Nicholus Malatji and Ojo Sunday Fayomi \\ Additional information is available at the end of the chapter
}

http://dx.doi.org/10.5772/62205

\begin{abstract}
Deterioration of metals and alloys during service due to corrosion and wear phenomena shortens materials' life span and structural integrity particularly in aggressive environments such as coastal and marine. This degradation also limits the use of these materials in most industrial applications. Therefore, the improvement of the quality of these materials in order to combat these challenges in industry remains critical. Surface modification techniques are employed to enhance materials' properties to enable better performance and to extend their applications in demanding environments. Electrodeposition has been a useful method developed to improve the corrosion and mechanical properties of materials. In the present contribution, ample knowledge about electrodeposition of $\mathrm{Zn}$ composite/nanocomposite coatings and their characteristics are reviewed to address coastal and marine degradation of metals and alloys.
\end{abstract}

Keywords: Corrosion Degradation, Mitigation, Nanocomposite, Electrodeposition, Tribology

\section{Introduction}

Metallic materials and structures (mainly steel) exposed to marine and coastal environments are constantly at risk of corrosion, which compromises their structural integrity and life span. Deterioration of materials due to corrosion can also have other serious implications such as economic costs, safety and environmental issues. The corrosion of these materials is induced by atmospheric pollutants mainly chloride ions. According to [1] the atmospheric salinity is dependent mainly on the distance from the sea shore (concentration of chloride salts is high near the shore and reduces with increasing distance from the shore) and wind. The salinity in marine and coastal atmosphere is caused by wind which stirs up and entrains sea water. The generated marine aerosol droplets are transported few hundred of meters inland by the same 
mechanism. Other factors that affect salinity include latitude, ruggedness of the coastline and undulation of the land surface. A high level of salinity is associated with accelerated corrosion rates and formation of unstable corrosion products [2]. Therefore, metallic structures found in marine and coastal environments have higher corrosion rates than those found inland (since chloride concentration is high close to the sea). Despite the magnitude of corrosion in the respective environments, prevention and combating corrosion remain critical to improve the service life of materials. Figures 1 and 2 show surface degradation induced by marine corrosion and the effect of atmosphere on the corrosion of low carbon steel.

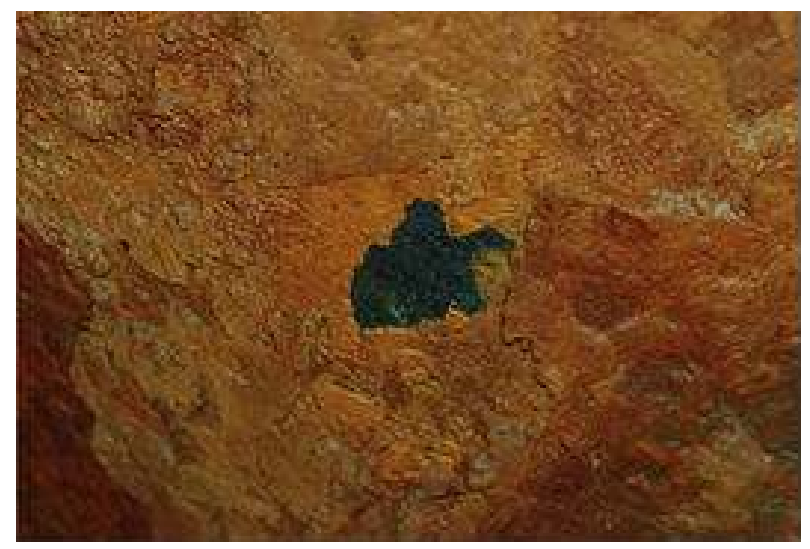

Figure 1. Accelerated Low Water Corrosion Observed on Steel Piles above Water during Spring Tide [2]

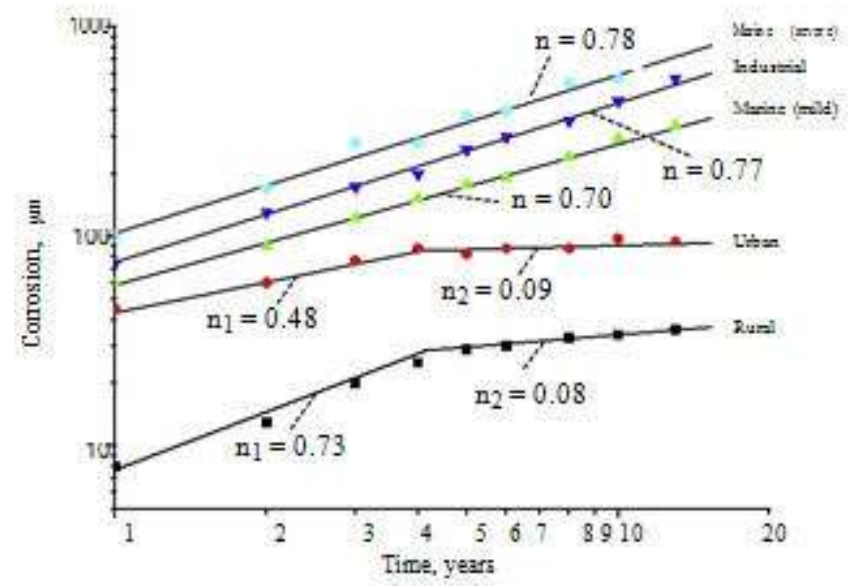

Figure 2. Effect of Atmosphere on the Corrosion of Mild Steel 
Surface modification and enhancement of properties of the base metal by applying protective coatings has played a significant role in the fight against corrosion. Coatings offer protective barrier between the corrosive environment and the substrate [3]. There are various types of protective coatings that range from nickel, copper, zinc, aluminium, etc., but this chapter focuses only on zinc coatings. Zinc coatings have been successfully used over the past decades to mitigate the corrosion deterioration of mild steel due to their good anti-corrosion properties, ease of fabrication and affordability. Zinc is more active than iron or steel and, thus, offers sacrificial protection to the base metal [4]. Several industries employ extensively this metal for protecting steel used in manufacturing of components, parts or structures against chemical or electrochemical degradation in rural, urban, industrial, coastal and marine atmospheric conditions [5]. However, the exposure of these coatings to aggressive conditions such as industrial, coastal and marine environments induces formation of white rust [6]. Basic reactions that take place during the corrosion of zinc are shown in Equations 1 and 2.

Anodic reaction:

$$
\mathrm{Zn} \rightarrow \mathrm{Zn}^{2+}+2 \mathrm{e}^{-}
$$

Cathodic reaction:

$$
\mathrm{O}_{2}+2 \mathrm{H}_{2} \mathrm{O}+4 \mathrm{e}^{-} \rightarrow 4 \mathrm{OH}^{-}
$$

Zinc oxides and hydroxides are commonly the main constituents in the corrosion products which form as a result of corrosion and tend to act as a passivation layer preventing further damage. However, the chemistry of the corrosion products depends on the level and nature of pollutants in the environment. The constituents of the corrosion products in various atmospheres are presented in Table 1. The presence of these atmospheric pollutants (chlorides, carbonates and sulphates) also promotes dissolution of the protective film and thus exposing the fresh metal for further deterioration. Other factors contributing to the degradation of zinc include time of exposure and wetness, $\mathrm{pH}$, stability of corrosion products, relative humidity and erosion [6-8].

To make zinc-based coatings to be strong and durable during application in harsh conditions, metals that are more chemically stable than the matrix are incorporated. Several metals such as aluminium, nickel, copper, cobalt, magnesium and manganese are added to fabricate zinc alloy coatings. These additions promote the evolution of uniform microstructure with limited surface defects and formation of stable and adherent passivation film that can withstand further attack. Many researchers have studied these coatings and found out that the coatings possessed not only excellent corrosion when compared to their traditional counterparts but also good mechanical properties [9-11]. Therefore, the incorporation of these elements into the coatings also extends their applications. The good performance of the coatings has made them to be substitute of cadmium sacrificial coatings and reduce the usage of organic chelating agents and chrome passivation that are not environmentally friendly [12-13] 


\begin{tabular}{|c|c|c|c|c|}
\hline Atmosphere & Test Site & Phases & Sulphate $\left(\mathrm{mg} / \mathrm{m}^{2}\right)$ & $\begin{array}{l}\text { Chloride } \\
\left(\mathrm{mg} / \mathrm{m}^{2}\right)\end{array}$ \\
\hline Rural & El Escorial & $\mathrm{ZnO}$ (zincite) & 267 & 143 \\
\hline Urban & Madrid & $\mathrm{ZnO}$ (zincite) & 609 & 106 \\
\hline Industrial & Bilbao & $\begin{array}{l}\mathrm{ZnO} \text { (zincite) } \\
\mathrm{Zn}_{4} \mathrm{SO}_{4}(\mathrm{OH})_{6} \cdot \mathrm{H}_{2} \mathrm{O} \text { (zinc } \\
\text { hydroxysulphate) }\end{array}$ & 1057 & 194 \\
\hline Marine & Barcelona & $\begin{array}{l}\mathrm{ZnO} \text { (zincite) } \\
\mathrm{ZnCO}_{3} \text { (smithsonite) } \\
\mathrm{Zn}_{5}(\mathrm{OH})_{8} \mathrm{Cl}_{2} \cdot \mathrm{H}_{2} \mathrm{O} \text { (simonkolleite) } \\
\mathrm{NaZn}_{4} \mathrm{Cl}(\mathrm{OH})_{6} \mathrm{SO}_{4} 6 \mathrm{H}_{2} \mathrm{O} \text { (sodium zinc } \\
\text { chlorohydroxysulphate) }\end{array}$ & 2592 & 5663 \\
\hline Marine & Alicante & $\begin{array}{l}\mathrm{ZnO} \text { (zincite) } \\
\mathrm{ZnCO}_{3} \text { (smithsonite) } \\
\mathrm{Zn}_{5}(\mathrm{OH})_{8} \mathrm{Cl}_{2} \cdot \mathrm{H}_{2} \mathrm{O} \text { (simonkolleite) } \\
\mathrm{NaZn}_{4} \mathrm{Cl}(\mathrm{OH})_{6} \mathrm{SO}_{4} 6 \mathrm{H}_{2} \mathrm{O} \text { (sodium zinc } \\
\text { chlorohydroxysulphate) }\end{array}$ & 3949 & 15261 \\
\hline
\end{tabular}

Table 1. Phases present and soluble salt contents from the corrosion products [6]

The ever changing and demanding industry calls for further advancement in the quality of the zinc coatings to cater for the new or improved applications. Exploration, investigation and development of new materials therefore remain critical to finding viable solutions for counteracting the change and demand. Metal oxides, carbides, nitride and so on have been codeposited with $\mathrm{Zn}$ to fabricate high corrosion, thermal and wear-resistant composite coatings. The incorporation of these particles into a metal matrix can be accomplished in micro, semi-micro and nano sizes. The composite dispersed particles in micro and semi micro size produced porous structured coatings which have limited corrosion control application. In search for more advanced materials that can cater for these limitations, nano-sized particles were found to have a potential that can eradicate the drawbacks associated with micro-sized particles [14].

Inclusion of nano-sized materials into a $\mathrm{Zn}$ matrix to produce nanocomposite coatings offers novel properties that are not exhibited by traditional coatings. The exotic properties such as excellent corrosion resistance, high temperature oxidation resistance, excellent self-lubricating and tribological properties possessed by these materials enable their extensive use for several applications [15]. The incorporation of the second phase particles into the matrix enable excellent performance of the resultant deposits in demanding environments such as coastal and marine. Nanoparticles of metal oxides, carbides, nitrides, borides, etc., have been used as bath additives to improve the properties of $\mathrm{Zn}$ matrix. The nanoparticles include $\mathrm{Al}_{2} \mathrm{O}_{3}, \mathrm{TiO}_{2}$, $\mathrm{CeO}_{2}, \mathrm{SiO}_{2}, \mathrm{SiC}, \mathrm{Si}_{3} \mathrm{~N}_{4}, \mathrm{TiN}, \mathrm{TiB}_{2}$, etc. 
Electrodeposition is one of the most important surface engineering techniques that is used for fabrication of Zn composite/nanocomposite coatings. This technique exhibits several advantages over the other deposition techniques. The advantages include low cost, versatility, simplicity of operation, high production rates and few size and shape limitations. The quality/ performance of the nanocomposite coatings produced by this process depend on a number of operating parameters that include particle concentration in the bath, $\mathrm{pH}$, temperature, current and bath agitation speed. These parameters need to be optimized to achieve the desirable coatings quality [16].

Fabrication and study of the properties of zinc composite/nanocomposite coatings using electrodeposition technique have not been thoroughly reviewed in literature. Therefore, this chapter focuses on providing ample information and in-depth analysis of the electrodeposition process (mechanism of incorporation of particles into a metal matrix and optimization of process parameters) and properties (morphological and structural characteristics, hardness, corrosion and wear) of the resultant deposits. This will help zinc electroplaters and corrosion engineers to understand zinc composite/nanocomposite electrodeposition to enable them to produce high quality coatings with improved functional properties.

\section{Fabrication of zinc alloy/composite coatings}

Application of coatings on metal surfaces that are prone to corrode is one of the most versatile methods that are employed to protect the metal from degradation. A coating acts as a physical barrier between the corrosive environment and metal, thus providing protection to the substrate from chemical deterioration. In tribological applications, the coating also offers load bearing capabilities. To ensure effective coating performance, the coating must be compatible with the substrate, have good adhesion and possess low porosity. Incorporation of reinforcement nanomaterials into the primary matrix to form composite coating enables production of coatings with advanced properties and good performance during application.

There are several techniques available for fabrication of composite coatings. These include, but not limited to, hot-dipping, thermal spraying, sol gel, vapour deposition, laser cladding, and electro- and electroless plating. The coatings resulting from these techniques exhibit different properties and find use in various applications.

\subsection{Hot dipping}

Hot-dip galvanizing is a deposition technique for coating iron or steel substrate with zinc by immersing the material of interest in a zinc molten bath [5]. This technique is a batch process and is mainly used on heavy structural steel sections. Galvanizing can be found in almost every major application and industry where iron or mild steel are employed. The surface of the steel requires preparation prior to deposition, and the preparation process includes the following steps:

1. Oil and grease are cleaned from the steel mostly with warm caustic soda to ensure proper chemical interaction between the substrate and molten zinc. 
2. The steel is then pickled in dilute solution of hydrochloric or sulphuric acid to remove rust and scale.

3. The steel is immersed in a fluxing bath containing ammonium chloride.

4. The fluxed large sections of steel are then directly dipped into the zinc molten bath for coating.

5. The hot-dip galvanized steel can sometimes be further treated by centrifuging method to reduce the excess zinc on the steel.

Coatings on small components, wires, tubes and sheets can be applied using continuous galvanizing process. The coatings produced by continuous galvanizing process are thinner than that of the batch hot dipping [17]. The bonding of the coating produced by hot dipping is promoted by the interaction of the molten zinc and iron in the steel to form a series of $\mathrm{Zn}$ Fe alloy [18]. The simplicity of galvanizing process enables wide range of applications in protection of steel more than other deposition techniques. The automotive industry is one of the industries that mostly depended on this process. The galvanized sheets are used for the assembling of the body of the car. Other automotive parts are also galvanized to protect them from corrosion attack [19].

\subsection{Thermal spraying}

Thermal spraying involves the melting and propulsion of metal particles onto a desired substrate using a spraying gun. The material (feedstock) which is to be applied as a coating is fed through the nozzle in a form of powder, wire or rod. It is fed with a stream of gas or air and is melted by a suitable gas-oxygen mixture. The melted material is propelled towards the surface to be coated and forms a consolidated coating on impact [17]. The three main variables that govern this process include the temperature of the flame, the velocity of the particles that are sprayed onto the work piece to fabricate a coating and the nature of the material used to form the coating. There are several types of thermal spraying, which include flame or torch, electric arc and plasma spraying. Thermal sprayed coatings can be made to have good adhesion, controlled thickness and can be applied to existing structures. Surface preparation is required to achieve good adhesion. Coatings fabricated by this technique possess strong bond with the substrate due to the interaction between the coating material and the steel. However, the fabrication of coatings using this technique requires high temperatures and the interaction between the substrate and the coating material makes it difficult to refurbish them when they are worn out.

\subsection{Laser cladding}

Laser cladding is another technique that is used to fabricate composite coatings on metal surfaces. This high energy technique employs laser beam to create a melt pool on the surface of the metal substrate in which the reinforcement powder is injected simultaneously. Coatings formed using laser cladding technique are dense and are employed in applications where good wear, corrosion and other surface-related properties are required. Laser cladding also has the 
capability to control composition and properties within a fabricated structure by either preblending or combining different elemental powders using multiple feeder systems at the laser focal zone, which enables tailoring of properties suited for specific engineering applications [20]. The use of laser in coatings technology is costly due to the high energy demand but still finds a variety of use in applications where durability and strength are required.

\subsection{Electrodeposition}

Electrodeposition is a technique that is used to apply adherent metallic coating on metal substrate by passing current between two electrodes immersed in an aqueous electrolyte containing ions of the metal of interest causing the metal ions to be deposited on the cathode. The anode is caused to be dissolved to replenish the metal ions in solution by flowing of current and make the cathode to be covered with the deposited metal [21]. Figure 3 shows a schematic diagram of a typical electrolytic cell used for the electrodeposition.

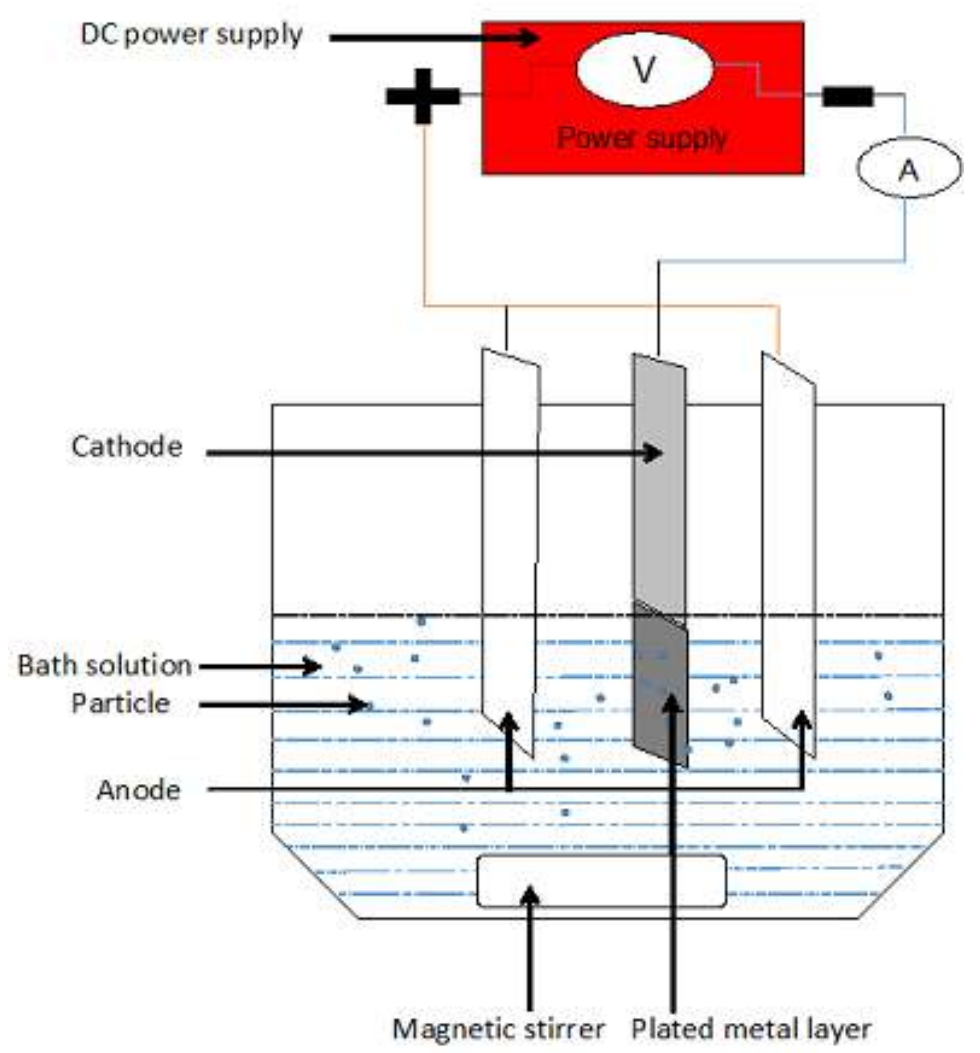

Figure 3. Typical Electrolytic Cell for Electrodeposition of Metals 
The reactions that take place during plating process can be depicted as follows:

Cathode reactions:

$$
\begin{aligned}
& \mathrm{M}^{\mathrm{n}+}+\mathrm{ne}^{-} \rightarrow \mathrm{M}^{\mathrm{o}} \\
& 2 \mathrm{H}^{+}+2 \mathrm{e}^{-} \rightarrow \mathrm{H}_{2}
\end{aligned}
$$

Anode reactions:

$$
\begin{gathered}
\mathrm{M}^{\mathrm{o}} \rightarrow \mathrm{M}^{\mathrm{n}+}+\mathrm{ne}^{-} \\
4 \mathrm{OH}^{-} \rightarrow 2 \mathrm{H}_{2} \mathrm{O}+\mathrm{O}_{2}+2 \mathrm{e}^{-}
\end{gathered}
$$

The quality of coatings produced by this technique depends on a number of operating parameters that include the bath composition, throwing power, temperature and bath agitation. Coatings exhibiting different properties such as microstructure, corrosion resistance, adhesion, thickness, hardness, thermal stability and wear resistance can be produced by manipulating these parameters. The flexibility of the electrodeposition enables the technique to find wide variety of applications in mitigation and control of corrosion mainly for small components. However, application of these coatings on large metal structures is beyond the capabilities of this process [21].

Electrodeposited coatings were primarily used for corrosion resistance and decoration (metal finishing). However, industrial technological advancement demand coatings that exhibit functional properties such as wear resistance, electrical properties, magnetic properties, solderability and thermal stability [22]. Zn electrodeposits are constantly improved to cater for this demand and electrodeposition technique makes coatings possible and simple at a lower cost compared to other deposition techniques.

\subsection{Electroless plating}

Electroless plating is a deposition technique used for coating metal bases by auto-catalytic or chemical reduction of metal ions without the application of external current. The internal current required for deposition is provided by the oxidation of reducing agents present in the solution. The quality of the coatings produced by this process makes it to gain more advantage over electrodeposition technique. The coatings exhibit excellent corrosion and wear resistance properties. The desired quality can be attained by controlling operating parameters such as temperature, $\mathrm{pH}$ and the composition of the bath. The bath constituents involved in electroless plating include metal ions source, reducing agent, buffering agent, complexing agent and wetting agent [23]. One of the most important bath constituent is a reducing agent since it supplies electrons to reduce metal ions to enable deposition. There are several available 
reducing agents, which include sodium hypophosphates, amino boranes, sodium borohydrides and hydrazines. Amongst them, sodium phosphates are commonly used due to lower costs and better corrosion resistance of the resulting coating. The reactions involved during electroless plating are as follows:

$$
\begin{gathered}
\mathrm{H}_{2} \mathrm{PO}_{2}^{-}+\mathrm{H}_{2} \mathrm{O} \rightarrow \mathrm{H}_{2} \mathrm{PO}_{3}^{-}+\mathrm{H}^{-}+2 \mathrm{e}^{-} \\
2 \mathrm{H}_{2} \mathrm{PO}_{2}^{-}+\mathrm{H}+\mathrm{e} \rightarrow \mathrm{P}+\mathrm{H}_{2} \mathrm{PO}_{3}{ }^{2-}+\mathrm{H}_{2} \mathrm{O}+\mathrm{H}_{2} \\
\mathrm{M}\left(\mathrm{NH}_{3}\right)_{\mathrm{n}}{ }^{2+}+2 \mathrm{e}^{-} \rightarrow \mathrm{M}+\mathrm{nNH}_{3} \\
2 \mathrm{H}^{+}+2 \mathrm{e}^{-} \rightarrow \mathrm{H}_{2}
\end{gathered}
$$

Electroless nickel coatings has assumed the greatest commercial importance among electroless coating. These coatings possess good surface properties, and incorporation of second phase particles enhances the characteristics of the resultant deposits. The second phase particles codeposited with the nickel include silicon carbide, aluminium oxide, carbon nanotubes, etc. The dispersion of these particles requires good bath stability, agitation, particle size, particle concentration and surfactants. This plating technique is complex, requires many additives, operates at elevated temperatures, contain phosphorus or borine and applicable for mostly nickel coatings.

\section{Composite electrodeposition}

\subsection{Mechanism of particle incorporation}

Researchers have attempted to investigate the mechanism of codeposition to understand the way particles are incorporated into metal matrix over the past decades. Many models have been developed which gives insight into the mechanism of codeposition of particles on the cathode. Most models that have been developed involve one or more of the following processes: (i) migration of the charged particles to the cathode by electrophoresis, (ii) adsorption of the particles on the surface of the electrode by van der Waals forces and (iii) mechanical incorporation of the particles into the layer [24]. In 1972, Guglielmi developed a two-step adsorption model that incorporates both adsorption and electrophoresis to describe the mechanism of particle codeposition. In the first step, the particles are covered with metal ions which cause them to be weakly adsorbed on the cathode. The second step includes the strong adsorption of the particles by Coulomb force which result in subsequent entrapment of the particles within the metal matrix [25]. The model has been accepted by many researchers; however, it excludes the particle characteristics and mass transfer during electrodeposition 
process. This model has been improved by other authors to eliminate the drawback associated with it. [26] used three modes of current density (low, intermediate and high) to differentiate the reduction of adsorbed ions on the particles. The model was developed to improve Guglielmi's model. It involves three steps, namely: (i) forced convective-diffusion of particles to the surface of the cathode, (ii) loose adsorption of particles on the cathode and (iii) irreversible incorporation of particles by reduction of adsorbed ions. Bercot et al. [27] improved Guglielmi's model by incorporating the corrective factor (third-order polynomial equation) to cater for its drawbacks. One model that has been greatly accepted by scholars is Kurozaki's model, which includes the movement of the particles to the cathode by mechanical agitation. This model involves three-step processes for incorporation of solid particles in to a metal matrix, which include:

1. Uniformly distributed particles are conveyed to the electric double layer by mechanical agitation.

2. Charged particles are transported to the cathode surface by electrophoresis.

3. Particles are adsorbed at the surface of the cathode due to the Coulomb force between the particles and adsorbed anions.

Figure 4 demonstrates the five consecutive steps involved in codeposition of particles into metal matrixes. The regions include formation of ionic cloud around the particles, convective movement towards the cathode (convection layer, typical length less $<1 \mathrm{~mm}$ ), diffusion through a concentration boundary layer (diffusion layer, typical dimensions of hundreds of $\mu \mathrm{m}$ ), electrical double layer (typical dimensions of $\mathrm{nm}$ ) followed by adsorption and entrapment of particles [28]. This model shows the step by step progression of particle codeposition from the electrolytic bulk solution until they are incorporated into the metal matrix. An electroactive cloud that surrounds the particles that are added into the electrolyte is created, which transport the covered particles to the hydrodynamic boundary layer through convection.

The particles migrate through this layer and are taken to the cathode through diffusion. The deposited and incorporated inert particles are embedded into the matrix by discharged metal ions after the ionic cloud is wholly or partially reduced [24]. The manner of incorporation of particles on the metal matrix depends mainly on the electrodeposition process parameters. Some of the most important parameters include the speed at which the bath is stirred, the applied current density and electrolyte composition. Bath agitation serve as a medium that assists particles to be transported to the cathode; while applied current density and electrolyte composition are responsible for the formation of ionic cloud around the introduced particles. There are three possibilities for particles to be incorporated into a metal matrix: (i) coatings that are just covered by adsorbed particles on the surface, (ii) coatings containing entrapped particles and (iii) coatings containing particles truly embedded uniformly into the metal matrix [29].

These three possibilities for explaining the manner of particle incorporation into the matrix is clearly demonstrated in Figure 5. 


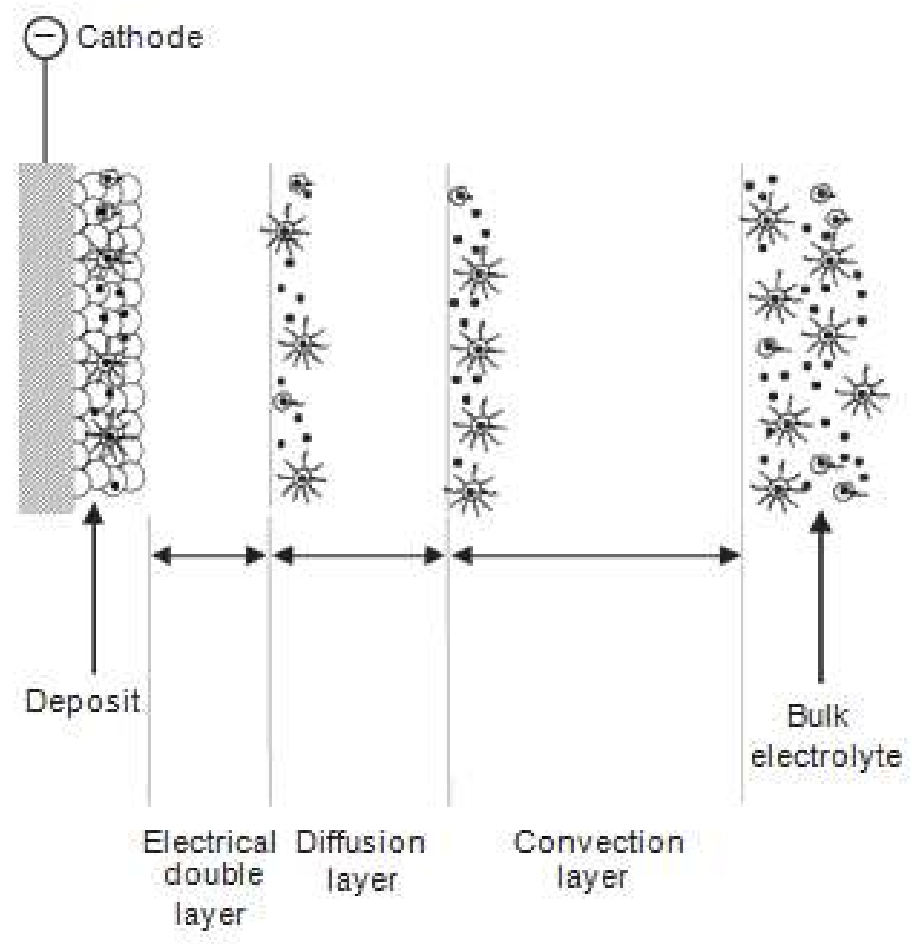

- Particles (conductive or non conductive)

a Surfactant (ionic, non-ionic or organic)

ॠ 'Clouding' of particles by surfactants

- 'Clouding' of particles by cations

Deposited metal

Figure 4. Codeposition Mechanism of Particles into a Metal Deposit [24]

The first type of coating that comprises many adsorbed particles on the surface is shown in Figure 5(a). These type of coatings exhibit inferior chemical, mechanical and thermal stability properties due to the unoccupied crevices, pores and microholes on the surface of the coatings. The localized inclusion of particles in the metal matrix as shown in Figure $5(b)$ is caused by agglomeration of particles in the solution and rapid deposition rate occurring as an effect of unoptimized process parameters. The poor performance of these coatings due to inhomogenous distribution of particles that causes surface defects does not allow them to be used for technological applications. The third coatings with truly homogenous and embedded particles within the matrix are corrosion and wear resistant possessing excellent microhardness [29] 
Nanocomposite coatings by electrodeposition

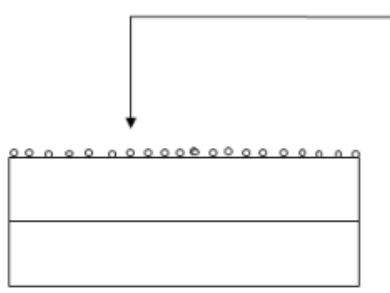

a) Particles adsorbed on the coating

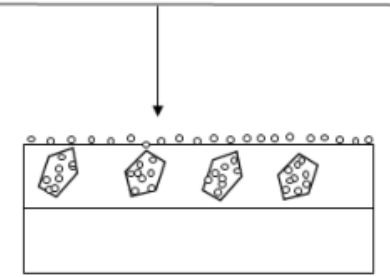

b) Particles entrapped inside the coating

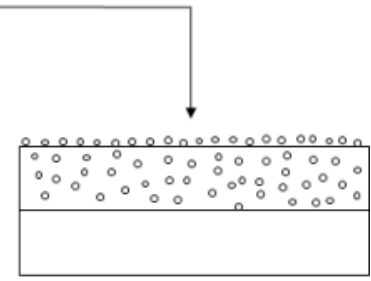

c) Particles embedded inside the coating

Figure 5. Schematic Representation of Different Codeposition Possibilities

\subsection{Effect of operating parameters}

Incorporation of composite nanoparticles into metal coatings depends mainly on the experimental parameters. The amount and nature of incorporation of the particles in the metal matrix determine the quality and success of the fabrication of the composite coatings. Several common process parameters and their effect on the properties of the coatings are discussed below.

\subsubsection{Applied current density}

Current is one of the important experimental parameters that require optimization in electrodeposition since the success of the process depends solely on current. The process uses electrical current to accelerate the dissolution and flowing of electrons to be deposited at the cathode. Studies have shown that at lower current densities, harder and brighter coatings with increased concentration of incorporated particles are formed. Current density of $0.8 \mathrm{~A} / \mathrm{cm}^{2}$ yielded microhardness value of $400 \mathrm{Hk}$, and increasing the current density to $1.6 \mathrm{~A} / \mathrm{cm}^{2}$ resulted in a decrease of $340 \mathrm{Hk}$. The mechanism of codeposition can be explained by the fact that at lower current densities, more time for achieving certain thickness is required compared to higher current densities. Due to this requirement, availability of particles at the cathode is raised and the possibility of the particles to be uniformly embedded in the coatings is increased. This results in formation of good quality composite coatings that can withstand trying environments [30]. [31] reported no significant effect on the microstructure and uniform distribution of $\mathrm{Al}_{2} \mathrm{O}_{3}$ nanoparticles in the nickel matrix due to the variation of current density from 0.01 to $0.03 \mathrm{~A} / \mathrm{cm}^{2}$. However, the concentration of the particles in the coatings was found to vary depending on the experimental condition (current density) the deposit was fabricated from. At low current density, increased concentrations of $\mathrm{Al}_{2} \mathrm{O}_{3}$ nanoparticles were present.

[32] studied the influence of applied current on the microstructure of electrodeposited ceria coatings for enhanced oxidation resistance of nickel-based alloy. The results showed that high applied current density lead to formation of crack network on the microstructure of the coatings. The development of the crack network was attributed to the rising of internal stresses 
caused by rapid deposition kinetics [32]. Increased current densities enhance the deposition kinetics and promote rapid codeposition, which forms coatings that exhibit no improved properties. Increased voltage gives results that are in contrast with findings obtained with variation of applied current density. Weight gain, brightness, fineness and adhesion were improved when applied voltage was increased from 0.6 to $0.8 \mathrm{~V}$ [33] Other reported work showed that cathode current efficiency was achieved at low current densities when the influence of process parameters on cathode current efficiency were studied on electrodeposition of $\mathrm{Zn}-\mathrm{SiO}_{2}$ composite coatings [34].

\subsubsection{Particle characteristics and concentration in the bath}

The size, shape, type and concentration of the particles used for the fabrication of composite coatings have significant influence on the manner of incorporation mechanism of codepostion and properties of the subsequent coatings. The incorporation of metal oxide, carbides, nitrides, borides and so on has been reported to exhibit excellent surface properties by several authors [24, 35-37]. However, it has been found that micron- and submicron-sized particles incorporated into the coatings leave surface defects such as microholes, pores and crevices on the metal matrix, which then serve as a weak site for material degradation when exposed to a corrosive medium [38]. Findings have shown that when the size becomes smaller there are high chances for more of the particles to be codeposited into the matrix. Solution where $300 \mathrm{~nm} \mathrm{Al}_{2} \mathrm{O}_{3}$ particles were used resulted in low amount of particles present in the nickel coatings compared to solutions where a size of $50 \mathrm{~nm}$ was used [38]. Nanoparticles possess excellent and exotic properties that are not contained in the bulk material even when they are of the same kind [15]. Incorporation of metal oxide, carbides and nitride nanoparticles yielded high microhardness, better corrosion resistance, good thermal stability and wear resistance [39, 36, 40].

The concentration of the particles in the electrolytic bath has significant effect on the properties of the coatings, and different particles reach optimum concentration in the solution at different bath loading levels. $\mathrm{ZrO}_{2}$ nanoparticles were found to yield best microhardness values when the bath loading was at $5 \mathrm{~g} / \mathrm{L}$ during their incorporation into a zinc matrix. The results showed a linear relationship between the particle concentration in the bath and their contents in the coating [36]. This behaviour is in harmony with Guglielmi's two-step adsorption model. A linear relationship between current efficiency and bath particle loading was observed by [34]. The increasing concentration of silica particles in the bath resulted in reduction of the current efficiency. The decrease might have been caused by solution resistance due to the increasing concentration of $\mathrm{SiO}_{2}$ particles in the solution. This contrasting result suggests that every particle has its own peculiar behaviour when added into bath solution and hence unpredictable. The work reported by [41] showed that the optimum particle loading for $\mathrm{Al}_{2} \mathrm{O}_{3}$ incorporated into $\mathrm{Zn}-\mathrm{Ni}$ matrix is $5 \mathrm{~g} / \mathrm{L}$ and deviation from this value resulted in poor electrochemical behaviour of the coatings. The reduced corrosion inhibition of the particles beyond the optimal concentration has been ascribed to agglomeration of the particles in the bath, leading to lack of availability of particles to be deposited on the cathode. Another reason is the development of poor quality coatings caused by the generation of defects in the coatings due to rapid codeposition. Nano- $\mathrm{Cr}_{2} \mathrm{O}_{3}$ was effective at $50 \mathrm{~g} / \mathrm{L}$ and increment to $75 \mathrm{~g} / \mathrm{L}$ resulted in no 
significant effect on the microhardness of nickel-based coatings [30]. Good anti-corrosive properties, better thermal stability and microhardness have been achieved by adjustment of bath particle of $\mathrm{SiO}_{2}$ to $5 \mathrm{~g} / \mathrm{L}$ in a $\mathrm{Zn}-\mathrm{Ni}$ matrix.

\subsubsection{Bath temperature}

Temperature does not play a major role in electrodeposition as it does in electroless plating, which depends mainly on the temperature and $\mathrm{pH}$ of the bath. However, increasing of temperature is known to enhance reaction rates in chemical processes. High temperatures increase the supply of ions to the cathode and the rate of nucleation of particles at the cathode [42]. This behaviour of the particle due to increases in the temperature has negative impact on the quality of the coatings. [12] reported the increase of the content of cobalt in zinc coatings due to the increment of temperature. However, raising the temperature was also found to reduce the polarization potentials and increase the amount of zinc in the deposit. So it is important for optimum temperature to be established to avoid all the drawbacks that are associated with increases in deposition temperature.

\subsubsection{Bath agitation}

The agitation of the bath during electrodeposition serves two functions: keeping the nanoparticles in suspension and the transportation of the particles to the cathode for codeposition. This actually explains that the incorporation of the particles in the metal matrix depends on the agitation speed of the bath during electrodeposition. Increasing of agitation speed improves the chance of the availability and adsorption of the particles by entrapment into the matrix. However, speeds beyond the optimal levels remove the particles from the cathode before they can be incorporated. The study of the effect of agitation speed on the microhardness revealed an increase in microhardness to maximum value of $395 \mathrm{Hk}$ at $400 \mathrm{rev} / \mathrm{min}$. Further increase to $600 \mathrm{rev} / \mathrm{min}$ had no effect on the microhardness of the coatings [30]. Agitation speeds of 900 and $1200 \mathrm{rev} / \mathrm{min}$ gave good microstructures when $\mathrm{SiC}$ particles were incorporated into a $\mathrm{Ni}$ matrix. Deviation from these values resulted in undesired appearance of microstructure, and it was concluded that the agitation must neither be too low or high but optimum [43].

Figure 6 demonstrates the effect of rotation speed on the incorporation of polytetrafluoroethylene (PTFE) particles in nickel coatings as studied by [27]. Different optimum rotation speeds were established, depending on the particle loading which is $500 \mathrm{rev} / \mathrm{min}$ at $10 \mathrm{~g} / \mathrm{dm}^{3}$, $600 \mathrm{rev} / \mathrm{min}$ at $20 \mathrm{~g} / \mathrm{dm}^{3}$ and $700 \mathrm{rev} / \mathrm{min}$ at $30 \mathrm{~g} / \mathrm{dm}^{3}$. Similar results were obtained when two baths were investigated for the effect of agitation speed on the current efficiency. The bath that contained $26 \mathrm{~g} / \mathrm{L} \mathrm{SiO}_{2}$ showed higher current efficiency compared with the bath loaded with $13 \mathrm{~g} / \mathrm{L}$. The increase in current efficiency was attributed to enhanced mass transfer due to agitation action [34]. These results showed that achieving optimum rotation speed depends on the particle concentration of the solution.

Figure 7 shows methods that are used in industry and laboratories to keep particles in suspension and transport them to the cathode during electroplating. These include physical dispersion of particles by bath agitation (mechanical stirrers, reciprocating plates, pumping, 


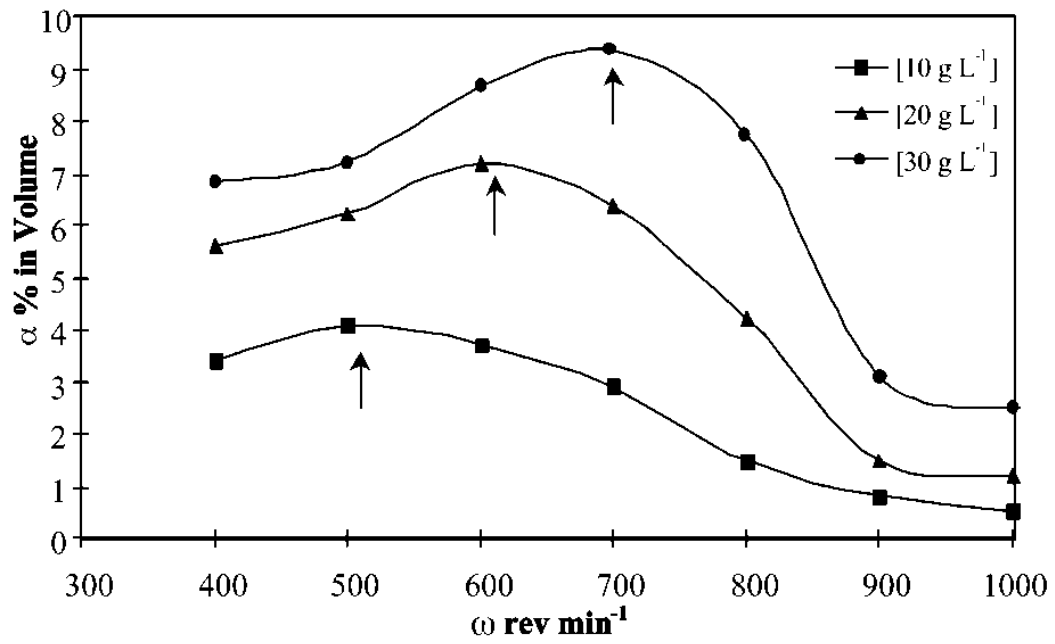

Figure 6. Effect of Stirring Speed on the Amount of PTFE Particles Embedded into Ni matrix, $10 \mathrm{~g} / \mathrm{L}, \circ 20 \mathrm{~g} / \mathrm{L}$ and $\mathbf{\nabla}$ $30 \mathrm{~g} / \mathrm{L}$ of PTFE particles [27]

rotating disk or cylinder electrodes and parallel plate channel flow) and chemical dispersion by surfactants (cationic surfactants or combination of cationic and anionic surfactants).

\subsubsection{Electrolytic $p H$}

Bath electrolytic $\mathrm{pH}$ has an influence on the behaviour of the bath since reactions can only occur under certain $\mathrm{pH}$ conditions. [45] reported an increase in deposition rate due to increasing electrolyte $\mathrm{pH}$ in electroless plating of $\mathrm{Ni}-\mathrm{Fe}-\mathrm{P}$ alloys. However, $\mathrm{pH}$ values higher than 9 was found to cause solution instability due to precipitation of ferrous hydroxide during plating. Hypophosphite oxidation influences the rate of deposition, and this reaction is dependent on the $\mathrm{pH}$ of the solution. Electrokinetic measurements showed $\mathrm{ZrO}_{2}$ nanoparticles were positively charged in $\mathrm{pH}$ less than 4 which aided the particles to be transported to the cathode. The addition of the particles in solutions of $\mathrm{pH} 3.5$ and 2.5 did not cause any new process, but some kind of surface blockage occurred on the electrode favouring reduction reactions [36]. The reduction reactions that could possibly occur are shown in Equations 11 and 12 below:

$$
\begin{aligned}
& \mathrm{H}_{3} \mathrm{O}^{3+}+2 \mathrm{e}^{-} \rightarrow \mathrm{H}_{2}+\mathrm{OH}^{-} \\
& 2 \mathrm{H}_{2} \mathrm{O}+2 \mathrm{e}^{-} \rightarrow \mathrm{H}_{2}+\mathrm{OH}^{-}
\end{aligned}
$$

The formation of inhibiting species such as hydrogen and nickel hydroxide depends on the $\mathrm{pH}$ of the bath and other process parameters. Hydroxide inhibiting species forms at high $\mathrm{pH}$, 
(a)

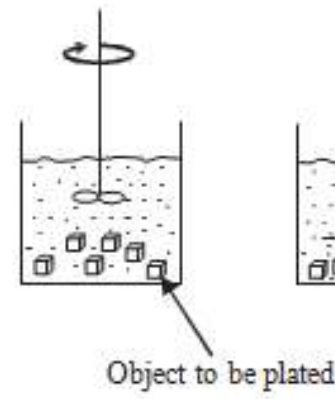

(d)

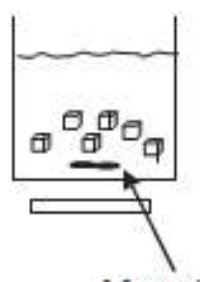

Magnetic bar (b)

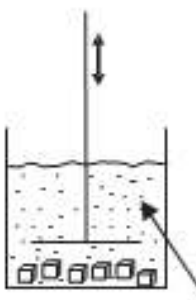

(c)

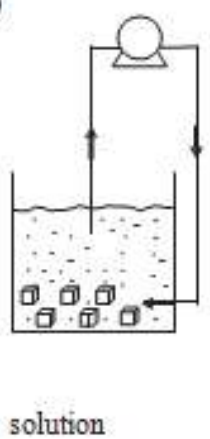

(f)

(e)

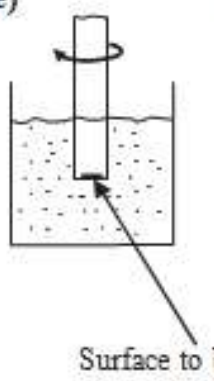

(g)

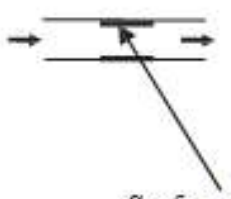

Surface to be plated

(h)

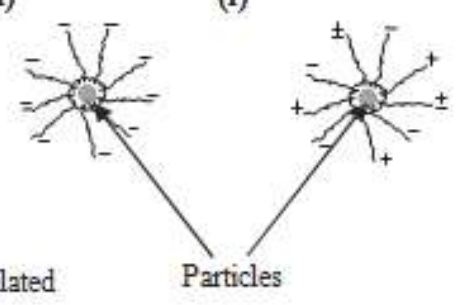

Figure 7. Bath Agitation Strategies: (a) Overhead Blade Stirrer; (b) Reciprocating Plate Plunger; (c) Pumped Electrolyte; (d) Magnetic Stirrer; (e) Rotating Disk; (f) Rotating Cylinder Electrode; (g) Flow between Parallel Plates; (h) Cationic Surfactant and (i) Combination of Ionic and Non-Ionic Surfactants [44]

and the evolution of hydrogen occurs at low $\mathrm{pH}$ as depicted by Equations 5 and 6 . The occurrence of this species affects the degree of texture of the coatings, and it can be easily controlled by adjusting the $\mathrm{pH}$. The preferential orientation of $\mathrm{Ni}-\mathrm{Cu}$ films of $(100)$ at $\mathrm{pH}$ between 3.3 and 2.6 was changed to (111) by changing the electrolytic $\mathrm{pH}$ to 2 [46]. [47] obtained insufficient zinc coating in the low current density region at low $\mathrm{pH}$ between 2.5 and 3.5. The increasing of the $\mathrm{pH}$ to 4 yielded satisfactory results with a bright and mirror finish deposit. Further increasing of the $\mathrm{pH}$ above 4.5 gave negative results and the deposit became dull. The activity of bath additives depends also on the electrolytic $\mathrm{pH}$, and hence it is important to optimize the $\mathrm{pH}$ when best results are sought. 


\subsubsection{Deposition time}

The thickness and the amount of incorporated nanoparticles in the composite coatings depend on the deposition time. [34] studied the effect of deposition time on the current efficiency of electrodeposited $\mathrm{Zn}-\mathrm{SiO}_{2}$ coatings. The current efficiency was found to increase with deposition time; the optimum time established was 180 seconds. Beyond this point, the current efficiency started to reduce which might be due to agglomeration of the particles in the bath. When these agglomerated particles are codeposited, blocking on the cathode due to the reduction of active surface area for deposition and a subsequent decrease in current efficiency occur [34]. Three distinct regions have been observed on the coating: a relatively compact underlayer of zinc, a discontinuous middle layer of dendritic trees of zinc with vertical silica in between and a topcoat of predominantly dense silica. The development and build up of these layers occur as a function of $\mathrm{pH}$ and time. The first layer of zinc forms with the good current efficiency due to the availability of the active surface area. The thickness of the coatings increases with time and $\mathrm{pH}$ also increases, causing agglomeration of particles in solution. The codeposition of the agglomerated particles reduce the active surface area and localized deposition, leading to the development of zinc dendritic 'trees' struggling to build up through the thick mass of silica top coat. The increase in the thickness of the coatings depends not only on the time but also on the bath particle loading. [48] obtained similar results when investigating the effect of time on the weight gain of zinc deposits.

[32] studied the influence of deposition time on the deposit growth, current density and coating thickness. Figure 8 shows the relationship between deposition time, deposit weight gain, thickness and the microstructures obtained from different deposition times. The results showed that deposit growth and thickness was not affected by the change in current density but increased with electrodeposition time. The deposit weight gain and thickness was constant up to 30 minutes of plating process. However, the coatings produced beyond 10 minutes of electrodeposition revealed a growing number of cracks [32].
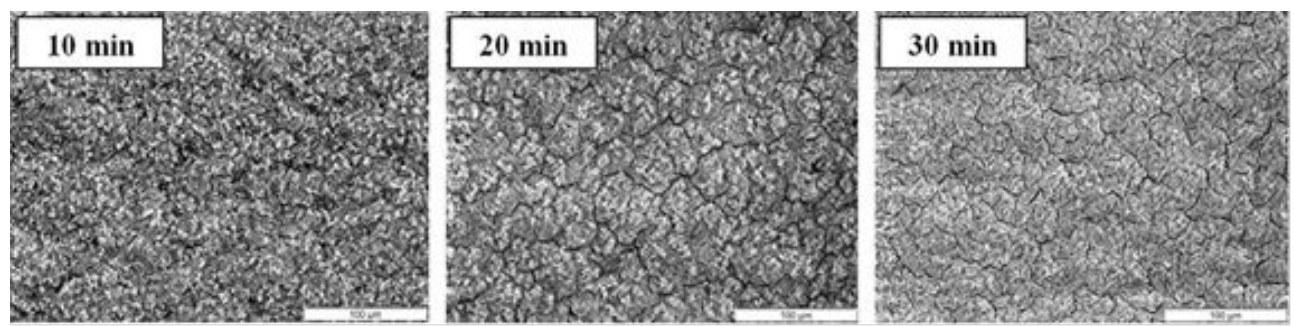

Figure 8. Surface Morphology of Electrodeposited Films with Increasing Time at Room Temperature in $0.1 \mathrm{~mol} / \mathrm{L}$ $\mathrm{Ce}\left(\mathrm{NO}_{3}\right)_{3} \cdot 6 \mathrm{H}_{2} \mathrm{O}$ for an Applied Density of $-1 \mathrm{~mA} / \mathrm{cm}^{2}$ [32].

\subsubsection{Chemical additives}

Chemical additives play a major role in electrodeposition. These chemical agents (surfactants and stabilizers) enhance the brightness, induce grain refinement and improve deposit prop- 
erties. The commonly used additives for electrodeposition of zinc include gelatin, dextrin, thiourea, glycin and glycerol [49]. Others that have been recently reported include CTAB (Cetyltriammonium Bromide), SDS (Sodium Dodecyl Sulphate), TEA and MEA [4, 36, 50]. Their addition during plating has a significant effect on the resultant deposits. They alter crystallographic orientation of the matrix and perturb grain growth, leading to microstructures with small-sized grains. High concentrations of the surfactant in the bath have been reported to positively affect the microstructural properties of the produced deposits [49]. The added additives also increased the content of the reinforcement particles and also control their distribution in the matrix.

\section{Properties of electrodeposited composite coatings}

Zinc matrix nanocomposite coatings find various applications in industry due to the unique properties that they exhibit over the traditional metal or alloy coatings. There are several composite coatings that have been produced using electrodeposition, but the ones that have received most commercial use include zinc and zinc-nickel nanocomposites. These novel coatings have been developed to meet the industrial demand and perform better under demanding environments at a reduced thickness than traditional coatings [29]. Zinc and zincnickel composite coatings exhibit enhanced properties such as self-healing properties, high hardness, good thermal stability, corrosion and wear resistance.

\subsection{Zn matrix composites}

Electrodeposition of zinc composite coatings is motivated by the development of novel coatings with enhanced surface properties for combating corrosion phenomena. Due to the ability of $\mathrm{Zn}$ to sacrificially protect steel from corrosion, it makes the metal to be an attractive matrix for fabrication of advanced composite coatings for demanding application. Several inert second phase particulates have been incorporated into the matrix, and improvement in the surface characteristics of the base coatings was achieved. The choice of the particles to be incorporated and formulation are guided by the properties expected to be achieved and potential applications where the coatings can be used. Single or double particle loading to fabricate binary and ternary composite coatings has been reported in literature.

\subsubsection{Composition, morphological and structural properties}

The incorporation of 5 and $10 \mathrm{~g} / \mathrm{L}$ of sub-micron $\mathrm{Al}_{2} \mathrm{O}_{3}$ into $\mathrm{Zn}$ matrix were found to follow the morphological orientation of $\mathrm{Zn}$ coating but with partial homogeneous structures [24]. The particles were also found to have no chemical interaction with the matrix, and the particle content in the coating was subject to the concentration of the particle in the plating bath. However, [51] reported formation of $\mathrm{Zn}_{\mathrm{x}} \mathrm{Sn}_{\mathrm{x}}$ phases when $\mathrm{SnO}_{2}$ was codeposited with $\mathrm{Zn}$. The chemical interaction observed in this work may be due to the change in operating parameters and bath formulations. The solubility of particles depends on various factors, and temperature and $\mathrm{pH}$ play a major role. Therefore, the difference obtained by the authors may be due to the 
increment of operating temperature to $40{ }^{\circ} \mathrm{C}$. The addition of $7 \mathrm{~g} / \mathrm{L}$ of the reinforcement particles yielded microstructures with no surface pores. The grain size was also found to be not dependent on the content of particles in the bath. [49] observed a correlation in bath particle loading and content of incorporated particles in the coating. Increasing particle concentration in the electrolyte solution improved the codeposition of the particles (bath solutions with high particle concentration yielded coatings with high particle content). This result is supported by Guglielmi's two-step adsorption model [25]. The model suggests that increasing the particle content in the bath increases their availability to the cathode thus enhancing codeposition.

\subsubsection{Corrosion resistance}

The main challenge that is faced by steels in marine and coastal environments is corrosion degradation, and enhanced corrosion resistance is one of the key properties that the fabricated coatings must exhibit. The chloride in the sea water accelerates material loss in this atmosphere. $\mathrm{Zn}-\mathrm{TiO}_{2}$ composite coatings exposed corrosive atmosphere of $3.65 \% \mathrm{NaCl}$ proved to possess better corrosion resistance than mild steel as studied by [35]. The embodiment of the particles brought a positive potential shift of $0.38 \mathrm{~V}$ and decreased the current density from 0.07 to $0.0000211 \mathrm{~A} / \mathrm{cm}^{2}$. Similar results were obtained by the authors when $\mathrm{SnO}_{2}$ particles were incorporated into the matrix. The inclusion of the second phase particles into the metallic matrix induces formation of stable film for further protection against corrosion. The passive film acts a physical barrier separating the fresh matrix from the corrosive media. The distribution of particles in the matrix also has a strong bearing on the corrosion resistance. Samples with uniform distributed particles have better anti-corrosive properties than those with agglomerated particles. Therefore, it is mandatory for the production of the composite coatings to be optimized to produce coatings with better particle dispersion and enhanced microstructure.

\subsubsection{Other properties}

\subsubsection{Hardness}

Incorporation of submicron particles into metal matrix is known mainly for their excellent improvement of mechanical properties. The fabrication of $\mathrm{Zn}$ composite coatings from baths solution containing 5 and $10 \mathrm{~g} / \mathrm{L}$ of submicron alumina particles drastically increased the hardness of $\mathrm{Zn}$ from 1.77 to 2.55 and $2.37 \mathrm{GPa}$, respectively [24]. The irregular morphological characteristics exhibited by samples fabricated from $10 \mathrm{~g} / \mathrm{L}$ might have been responsible for reduction in hardness. Incorporation of second phase particles into the matrix impedes the growth of grains leading to the formation of microstructures with small-sized crystals [36]. Therefore, uneven distribution of particles in the matrix promotes formation of microstructures with chemical and physical inhomogeneity. Multiple loading of particles has also been found to improve the matrix by [52]. The incorporation of TiC-TiB mixed ceramic particles into $\mathrm{Zn}$ matrix have positive synergetic effect on the mechanical properties. The ternary composite exhibited high hardness values as compared to $\mathrm{Zn}-\mathrm{TiC}$ and $\mathrm{Zn}-\mathrm{TiB}$. The synergetic properties of the mixed reinforcement particles improve the properties of the individual ones. 


\subsubsection{Wear resistance}

Wear resistance is one of extractive properties that coatings should possess for durability and increased life span during service. However, zinc coatings are known for their poor performance when they are subject to wear environment. The development of composite coatings also aims at improving this property to extend the applications of the coatings. The inclusion of reinforcement particles hinder plastic deformation due to the dispersive strengthening effect exhibited by the particles [51]. The authors also reported that the alteration of microstructure and strengthening of the coatings by formation of compact and crack-free coating add to the minimization of friction due to the presence of embedded particles The particles also form a protective barrier between the matrix and the wearing medium, thus reducing direct contact and friction coefficient [53].

\subsection{Zn nanocomposite coatings}

\subsubsection{Morphological and structural properties}

The inclusion of nanoparticles in a metal matrix has been reported to induce grain refinement and modify the structural characteristics of the matrix. During codeposition, second phase particles are adsorbed on the growing crystal and retard its further growth. The adsorbed particles increase the number of nucleation sites, which results in reduction of the grain size [36]. The morphology of composite coatings depends mainly on the manner of particle dispersion and content of particles in the metal matrix [4]. Morphological and structural analysis results obtained by [54] revealed a reduction of crystal size of $\mathrm{Zn}$ matrix due to the incorporation of $\mathrm{TiO}_{2}$ nanoparticles. The nanocomposite coating followed the same morphological pattern with the matrix, but with smaller and smooth grains. The deposits also showed minimal surface defects such as pores and microholes. $\mathrm{Zn}-\mathrm{TiO}_{2}$ nanocomposites produced from baths containing the highest particle concentration $(16 \mathrm{~g} / \mathrm{L})$ have been reported to affect the morphology of the plain Zn coatings [37]. The nanocomposite coatings exhibited surface morphology different from the matrix. High particle content and orientation of particles (agglomeration) in the coating causes an evolution of a new structure. The introduction of SiC were found to cause deposition overpotential leading to the formation of coatings with grains perpendicularly oriented to the substrate as compared to the parallel hexagonal plates showed by $\mathrm{Zn}$ matrix [55]. The incorporation of the particles onto the cathode was also reported to perturb horizontal grain growth in the coatings. Therefore, the morphological characteristics of the coatings depend solely on the bath parameters and formulation.

\subsubsection{Corrosion resistance}

Addition of second phase particles to $\mathrm{Zn}$ matrix promotes the formation of fine microstructure with good corrosion resistance. The particles perturb the growth of $\mathrm{Zn}$ crystals and induce the formation of new nucleation sites resulting in small-sized crystals and a microstructure with minimal defects [13]. Uniform dispersion of the nanoparticulates in the matrix fills the microholes, pores, crevices, gaps and other surface defects of the coatings leading to the formation of compact microstructures. These defects can serve as active sites for corrosion if 
present. The particles have also been reported to act as physical barriers between corrosive media and the matrix, thus minimizing the occurrence of defect corrosion [55]. Codeposition of black carbon nano-sized particles with Zn reduced the current density when the coatings were tested in $3.5 \%$ sodium chloride solution [56]. The metal dissolution of the composites was also found to occur at high anodic potentials at a steady rate as compared to the Zn coating. [36] reported zirconia nanoparticles to influence the kinetics of the anodic and cathodic electrochemical reactions. Therefore, the particles can promote the perturbation of anodic reaction and favour the formation of a stable passivation layer. Therefore, the presence of second phase particles in the matrix has positive effect on the corrosion resistance of the coatings. However, optimum particle loading has to be established to obtain coatings with enhanced anti-corrosive properties. Agglomeration of particles in the coating was found to occur when $\mathrm{Al}_{2} \mathrm{O}_{3}$ and $\mathrm{SiO}_{2}$ particle contents in the electrolyte solution were beyond optimal concentrations [57]. The authors established optimal particle loading for excellent corrosion resistance is $5 \mathrm{~g} / \mathrm{L}$ for both $\mathrm{Al}_{2} \mathrm{O}_{3}$ and $\mathrm{SiO}_{2}$. Beyond these optimal conditions, the corrosion resistance of the coatings was compromised. Incorporation of non-uniform agglomerates in the matrix promotes formation of surface defects and causes chemical heterogeneities in the coating. This allows penetration of the corrosive media into the matrix in weak sites, leading to the degradation of the corrosion resistance of the entire system.

\subsubsection{Other properties}

\subsubsection{Hardness}

Microhardness of a metal matrix mainly depends on the microstructural properties of that particular matrix. When force or load is exerted on a material, the dislocation movements are induced which lead to the weakening of the material's mechanical properties [58]. Incorporation of nanoparticles into a matrix perturbs dislocation movement and grain boundary sliding, thus improving the hardness of the composite coatings. Grain refinement and uniform incorporation of reinforced particles result in improvement of hardness. [56] obtained an increase in microhardness from 72 to $90 \mathrm{HV}$ when $2 \mathrm{~g} / \mathrm{L}$ of nano-sized carbon particles were incorporated into Zn matrix. The composite coating also showed improved morphology with small-sized crystals. Another factor that affects microhardness of a $\mathrm{Zn}$ matrix is the content of the reinforcement material added into the coating. The increase of bath particle content increases the chances of the particles to be incorporated into the metal matrix [54-55].

\subsubsection{Wear resistance}

The coatings' resistance to wear degradation is one of the important properties sought for metal matrix composites to exhibit. Many industrial applications where these coatings are employed require them to possess excellent wear resistance. The addition of reinforcement into a metal matrix promotes grain reduction and hinders plastic deformation of the material [59]. This is attributed to particles' grain refining and dispersive strengthening characteristics exhibited by these additives. The reinforcement particles also possess self-lubricating properties and hence reduce friction, thus improving the wear resistance of the matrix. The incorporation of nanosized $\mathrm{TiO}_{2}$ into $\mathrm{Zn}$ matrix carried out by [54] reduced the wear loss of $\mathrm{Zn}$ from 11 to $5 \mathrm{mg}$. The 
results obtained by [35] showed an improvement in wear resistance and reduction of friction coefficient of the $\mathrm{Zn}$ matrix due to the addition of $\mathrm{TiO}_{2}$ particles.

\subsection{Zn alloy nanocomposite coatings}

There are several zinc alloy nanocomposite coatings ranging from $\mathrm{Zn}-\mathrm{Ni}$, Zn-Co, Zn-Fe, etc. to matrix-based composites. Zn-Ni matrix nanocomposites have received much attention as compared to the others. Nickel is chemically stable and has better mechanical properties than $\mathrm{Zn}$, and its incorporation into $\mathrm{Zn}$ matrix notably improves the corrosion and wear resistance of the coatings.

\subsubsection{Composition, morphological and structural properties}

Uniformly distributed nano-sized $\mathrm{Al}_{2} \mathrm{O}_{3}$ incorporated into $\mathrm{Zn}-\mathrm{Ni}$ matrix improves the compaction of grains in the coatings and minimizes surface defects [60]. The crystallite size of $\mathrm{Zn}$ $\mathrm{Ni}$ matrix was reduced from 40.9 to $20.68 \mathrm{~nm}$. The crystallite size was found to be dependent on the particle content of nano- $\mathrm{Al}_{2} \mathrm{O}_{3}$ present in the solution. The authors also reported the increment of nickel content in the coatings due to the addition of the reinforcement particles. The work conducted by [41] confirms these findings. $\mathrm{Zn}_{5} \mathrm{Ni}_{21}$ phase was increased as the result of incorporation of the nanoparticles into the matrix. [39] also showed similar results when $\mathrm{SiO}_{2}$ nanoparticles were added. The nickel content was increased from 6.3 to $12.3 \mathrm{wt}$.\% while zinc was decreased from 93.7 to $87.7 \mathrm{wt}$.\%. Inclusion of particles into the matrix has significant influence on the surface morphology of the resulted deposits. $\mathrm{Al}_{2} \mathrm{O}_{3}$ solutions changed hemispherical nodules of $\mathrm{Zn}-\mathrm{Ni}$ to cauliflower-like surface morphology [61].

\subsubsection{Corrosion resistance}

The automobile industry extensively uses Zn-Ni coatings for corrosion protection of steel. These coatings are chemically stable than their zinc counterparts. Addition of second phase nanoparticles into $\mathrm{Zn}-\mathrm{Ni}$ enhances anti-corrosive and mechanical properties. $\mathrm{Al}_{2} \mathrm{O}_{3}$ nanoparticles have been incorporated into $\mathrm{Zn}-\mathrm{Ni}$ matrix from alkaline solutions by [41] The coatings fabricated from baths containing $5 \mathrm{~g} / \mathrm{L} \mathrm{Al}_{2} \mathrm{O}_{3}$ possessed excellent corrosion resistance when tested in $0.2 \mathrm{~g} / \mathrm{L} \mathrm{Na}_{2} \mathrm{SO}_{4}$ electrolyte. The corrosion current was drastically reduced, and the polarization resistance increased. These findings are similar to those obtained by [60] where the current density was decreased from 0.19 to $0.092 \mu \mathrm{A} / \mathrm{cm}^{2}$. The results obtained by the authors show that the particles impart inhibitory effect to the corrosion of the matrix. $\mathrm{Al}_{2} \mathrm{O}_{3}$ particles exhibit low level of electronic conductivity and can disturb corrosion current when they present in the coating. $\mathrm{SiO}_{2}$ nanoparticles codeposited with $\mathrm{Zn}-\mathrm{Ni}$ matrix have reported to protect the matrix from corrosion in $3 \% \mathrm{NaCl}$ solution [39]. Electronegative $\mathrm{Zn}$ rich $\eta$ phase has been found to improve the protective life of the coatings.

\subsubsection{Other properties}

Other properties that $\mathrm{Zn}-\mathrm{Ni}$-based nanocomposite coatings possess include high hardness and good thermal stability. [60] obtained improvement of microhardness of $640 \mathrm{HV}$ when they 
incorporated $\mathrm{Al}_{2} \mathrm{O}_{3}$ nanoparticles into $\mathrm{Zn}-\mathrm{Ni}$ matrix with the aid of ultrasound for bath agitation. $\mathrm{Zn}-\mathrm{Ni}-\mathrm{SiO}_{2}$ nanocomposite coatings produced from bath containing $5 \mathrm{~g} / \mathrm{L} \mathrm{SiO}_{2}$ increased the microhardness value of the matrix from 140 to $396 \mathrm{HV}$ [39]. The microhardness values of the composite remained higher than that of the matrix even when the samples were subjected to annealing temperatures of $200{ }^{\circ} \mathrm{C}$ for a duration of 24 hours (shown in Figure 9) Second phase reinforcement particles have pinning effect on the grain growth of the coatings due to elevated temperatures. The particles reduce surface oxidation and relaxation of internal stressed.

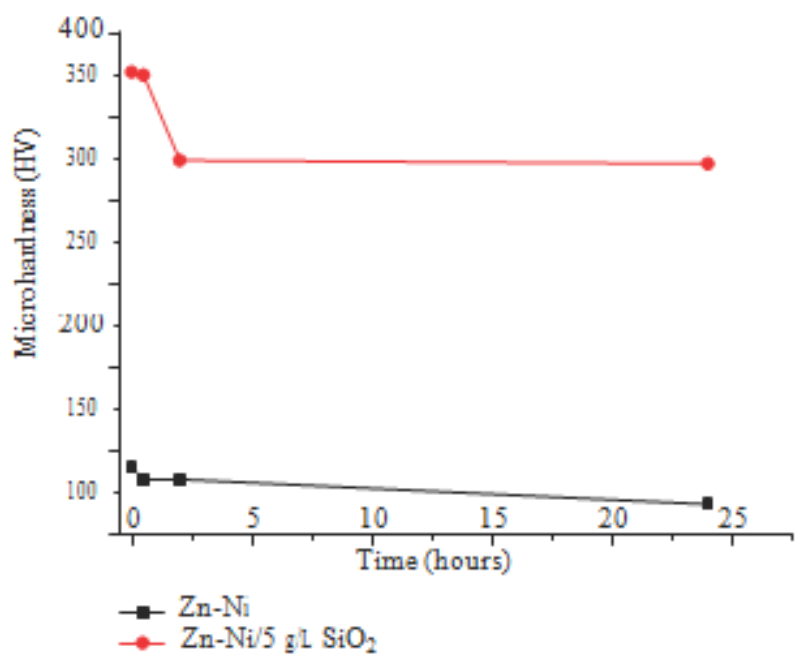

Figure 9. Microhardness evolution of $\mathrm{Zn}-\mathrm{Ni}$ and $\mathrm{Zn}-\mathrm{Ni}-\mathrm{SiO}_{2}$ nanocomposite coatings subjected to heat treatment conditions of $200{ }^{\circ} \mathrm{C}$ for $0.5,2$ and 24 hours time range.

\section{Conclusions}

From the current review, it can be concluded that electrodeposited Zn composite coatings have high potential to serve as protective films for protecting components and pieces that are made of mild steel from corrosion in coastal and marine environments. Their improved surface properties such as corrosion resistance, high hardness, low friction and wear resistance due to the incorporation of second phase particles enable them to find various applications. The advantage of inclusion of inert ceramic particles in metal deposits is that harder, and chemically stable coatings can be produced at reduced thickness. However, the quality of electrodeposited coatings is not dependent on the presence of reinforcement particles only but on a number of process parameters $(\mathrm{pH}$, plating current, temperature, deposition time, stirring speed and bath composition); hence, optimization of the process is required to produce desired 
and high quality coatings. More work on further improvement of electrodeposited zinc coatings is required to enable them to serve as alternative or replacements to other coatings produced by high cost and energy intensive surface modification processes.

\section{Author details}

Patricia A.I. Popoola*, Nicholus Malatji and Ojo Sunday Fayomi

*Address all correspondence to: popoolaapi@tut.ac.za

Department of Chemical, Metallurgical and Materials Engineering, Tshwane University of Technology, Pretoria, South Africa

\section{References}

[1] Alcantara, J., Chico, B., Diaz, I., de la Fuente, D. \& Morcillo, M. 2015. Airborne Chloride Deposit and its Effect on Marine Atmospheric Corrosion of Mild Steel. Corrosion Science, $97,74-88$.

[2] James, M.N. \& Hattingh, D.G. 2015. Case Studies in Marine Concentrated Corrosion. Engineering Failure Analysis, 47, 1 - 15.

[3] Popoola, A.P.I., Olorunniwo, O.E. \& Ige, O.O. 2014. Developments in Corrosion Protection.Intech.

[4] Ranganatha, S. Venkatesha, T.V. Vathsala, K. \& Punith Kumar, M.K. 2012. Electrochemical Studies on $\mathrm{Zn} /$ nano- $\mathrm{CeO}_{2}$ Electrodeposited Composite Coatings. Surface $\mathcal{E}$ Coatings Technology, 208, 64-72.

[5] Roberge, P.R. 2008. Corrosion Engineering, Principles and Practice. New York, NY: McGraw Hill.

[6] De La Fuente, D., Castano, J.G. \& Morcillo, M. 2007. Long-term Atmostpheric Corrosion of Zinc. Corrosion Science, 49, 1420 - 1436.

[7] Azmat, N.S., Ralston, K.D., Muddle, B.C. \& Cole, L.S. 2011. Corrosion of Zn under Acidified Droplets. Corrosion Science, 53, 1604- 1615.

[8] Veleva, L., Acosta, M. \& Meraz, E. 2009. Atmospheric Corrosion of Zinc Induced by Runoff. Corrosion Science, 51, 2055 - 2062.

[9] Sylla, D., Creus, J., Savall, C., Roggy, O., Gadouleau, M. \& Refait, P.H. 2003. Electrodeposition of Zn-Mn Alloys on Steel From Acidic Zn-Mn Chloride Solutions. Thin Solid Films, 424, 171-178. 
[10] Hosking, N.C., Strom, M.A., Shipway, P.H. \& Rudd, C.D. 2007. Corrosion Resistance of Zinc-Magnesium Coated Steel. Corrosion Science, 49, 3669-3695.

[11] Popoola, A.P.I \& Fayomi, O.S. 2011b. Performance Evaluation of Zinc Deposited Mild Steel in Chloride Medium. International Journal of Electrochemical Science, 6, 3254 3263.

[12] Lodhi, Z.F., Mol, J.M.C., Hovestad, A., Terryn, H. \& DE Wit J.H.W. 2007. Electrodeposition of Zn-Co and Zn-Co-Fe Alloys from Acidic Chloride Electrolytes. Surface $\mathcal{E}$ Coatings Technology, 202, 84-90.

[13] Punith Kumar, M.K \& Srivastava, C. 2013. Morphological and Electrochemical Characterization of Electrodeposited Zn-Ag Nanoparticle Composite Coatings. Material Characterization, 85, 82-91.

[14] Benea, L., Bonora, P.L., Borello, A. \& Martelli, S. 2001. Wear Corrosion Properties of Nanostructured Sic-Nickel Composite Coatings obtained by Electroplating. Wear, 249, 995-1003.

[15] Khan, W.S. \& Asmatulu, R. 2013. Nanotechnology Emerging Trends, Markets, and Concerns. Nanotechnology Safety. Amsterdam: Elsevier.

[16] Tjong, S.C. \& Chen, H. 2004. Nanocrystalline Materials and Coatings. Materials Science Engineering, 45, 1-88.

[17] Chandler, K.A. \& Bayliss D.A. 1985. Corrosion Protection of Steel Structures. England: Elsevier Applied Science Publishers Ltd.

[18] Revie, R.W. \& Uhlig, H.H. 2008. Corrosion and Corrosion Control: An Introduction to Corrosion Science and Engineering. New York: John Wiley and Sons, Inc.

[19] Park, H. 1997. The Role of Texture and Morphology in Optimizing the Corrosion Resistance of Zinc-based Electrogalvanized Coatings. D.Phil. Thesis. Montreal. McGill University.

[20] Palcic, I., Balazic, M., Milfelner, M. \& Buchmeister, B. 2009. Potential of Laser Engineered Net Shaping (LENS) Technology. Materials and Manufacturing Processes, 24(78), 750-753.

[21] Mudali, U.K. \& RAJ, B. 2008. Corrosion Science and Technology: Mechanisms, Mitigation and Monitoring. New Delhi: Narosa Publishing House.

[22] Nemes, P.L., Lekka, M., Fedrizzi, L. \& Muresan, L.M. 2014. Influence of the Electrodeposition Current Regime on the Corrosion Resistance of $\mathrm{Zn}-\mathrm{CeO}_{2}$ Nanocomposite Coatings. Surface Coatings and Technology, 252, $102-107$.

[23] Sudagar, J., Lian, J. \& Sha, W. 2013. Electroless Nickel, Alloy, Composite and Nano Coatings - A Critical Review. Journal of Alloy and Compounds, 571, 183-204. 
[24] Sancakoglu, O., Culha, O., Toparli, M., Agaday, B., \& Celik, E. 2011. Co-deposited Zn-submicron Sized $\mathrm{Al}_{2} \mathrm{O}_{3}$ Composite Coatings: Production, Characterization and Micromechanical Properties. Materials and Design, 32, 4054-4061.

[25] Guglielmi, N. (1972). Kinetics of the Deposition of Inert Particles from Electrolytic Baths. Journal of the Electrochemical Society, 119, 1009-1012.

[26] Hwang, B.J. \& Hwang, C.S. 1993. Mechanism of Codeposition of Silicon Carbide with Electrolytic Cobalt. Journal of Electrochemical Society, 140, 979-984.

[27] Bercot, P., Pena-Munoz, E. \& Pagetti. 2002. Electrolytic Composite Ni-PTFE Coatings: An Adaptation of Guglielmi's Model for the Phenomena of Incorporation. Surface Coatings Technology, 157, 282.

[28] Roos, J.R., Celis, J.P., Fransaer, J. \& Buelens, C. 1990. The Development of Composite Plating for Advanced Materials. Journal of Materials, 42, 60-73.

[29] Khan, T.R., Erbe, A., Auinger, M., Marlow, F. \& Rohwerder, M. 2011. Electrodeposition of Zinc-silica Composite Coatings: Challenges in Incorporating Functionalized Silica Particles into a Zinc Matrix. Science and Technology of Advanced Materials, 12(5), $1-9$.

[30] Srivastava, M. Balaraju, J.N., Ravishankar, B. \& Rajam, K.S. 2010. Improvement in the Properties of Nickel by Nano- $\mathrm{Cr}_{2} \mathrm{O}_{3}$ Incorporation. Surface \& Coatings Technology, 205, 66-75.

[31] Saha, R.K. \& Khan, T.I. 2010. Effect of Applied Current on the Electrodeposited Ni$\mathrm{Al}_{2} \mathrm{O}_{3}$ Composite Coatings. Surface Coatings and Technology, 205, 890-895.

[32] Bouchaud, B., Balmain, J., Bonnet, G. \& Pedraza, F. 2013. Optimizing Structural and Compositional Properties of Electrodeposited Ceria Coatings for Enhanced Oxidation Resistance of a Nickel-based Superalloy. Applied Surface Science, 268, 218-224.

[33] Popoola, A.P.I. \& Fayomi, O.S.I. 2011a. Effect of Some Process Variables on Zinc Coated Low Carbon Steel Substrates. Scientific Research and Essays, 6(20), 4264-4272.

[34] Tuaweri, T.J., Adigio, E.M. \& JOMBO, P.P. 2013. Influence of Process Parameters on the Cathode Current Efficiency of $\mathrm{Zn} / \mathrm{SiO}_{2}$ Electrodeposition. International Journal of Mechanical Engineering and Applications, 1(5), 93-99.

[35] Fayomi, O.S.I., Popoola, A.P.I. \& Loto, C.A. 2014. Tribo-Mechanical Investigation and Anti-Corrosion Properties of $\mathrm{Zn}-\mathrm{TiO}_{2}$ Thin Film Composite Coatings from Electrolytic Chloride Bath. International Journal of Electrochemical Science, 9, 3885 - 3903.

[36] Vathsala, K. \& Venkatesha, T.V. 2011. Zn- $\mathrm{ZrO}_{2}$ Nanocomposite Coatings: Electrodeposition and Evaluation of Corrosion Resistance. Applied Surface Science, 257, 8929 8936. 
[37] Fustes, J., Gomes, A. \& Da Silva Pereira, M.I. 2008. Electrodeposition of $\mathrm{Zn}-\mathrm{TiO}_{2}$ Nanocomposite Films-effect of Bath Composition. Solid State Electrochemistry, 12, 1435-1443.

[38] Low, C.T.J., Wills, R.G.A. \& Walsh, F.C. 2006. Electrodeposition of Composite Coatings Containing Nanoparticles in a Metal Deposit. Surface \& Coatings Technology, 201, 371-383.

[39] Hammami, O., Dhouibi, L., Bercot, P., Rezrazi, E. \& Triki, E. 2011. Study of Zn-Ni Alloy Coatings Modified by $\mathrm{Nano}-\mathrm{SiO}_{2}$ Particles Incorporation. International Journal of Corrosion, 12, 1-8.

[40] Lee, C.K. 2012. Wear and Corrosion Behavior of Electrodeposited Nickel-Carbon Nanotube Composite Coatings on Ti-6Al-4V Alloy in Hanks' Solution. Tribology International, 55, 7-14.

[41] Blejan, D. \& Muresan, L.M. 2013. Corrosion Behavior of $\mathrm{Zn}-\mathrm{Ni}-\mathrm{Al}_{2} \mathrm{O}_{3} \mathrm{Nanocomposite}$ Coatings Obtained by Electrodeposition from Alkaline Electrolytes. Materials and Corrosion, 64, 433-438.

[42] Muralidhara, H.B., Arthoba Naik, Y., Balasubramanyam, J., YOGESH KUMAR, K., H. \& VEENA, M.S. 2012. Nanocrystalline Zinc Coating on Steel Substrate using Condensation Product Of Glycyl-Glycine (GGL) and Vanillin (VNL) and Its Corrosion Study. International Journal of Chemical Sciences, 10(1), 524-538.

[43] Zhau-XIA, N., Fa-He, C., Wei, W., Zhau, Z., Jian-Qing, Z. \& CHU-NAN, C. 2007. Electrodeposition of Ni-SiC Nanocomposite Film. Transaction of Nonferrous Metals Society of China, 7, 9-15.

[44] Helle, K. \& Walsh, T.F. 1997. Electrodeposition of Composite Layers Consisting of Inert Inclusions in a Metal Matrix. Transactions of the Institute of Metal Finishing, 75, 5358.

[45] WANG, S. 2004. Studies of Electroless Plating of Ni-Fe-P Alloys and the Influences of Some Deposition Parameters on the Properties of the Deposits. Surface Coatings and Technology, 186, 372-376.

[46] Haciismailoglu, M. \& Alper, M. 2011. Effect of Electrolyte pH and Cu Concentration on Microstructure of Electrodeposited Ni-Cu Alloy Films. Surface E Coatings Technology, 206, 1430-1438.

[47] Naik, Y.A., Venkatesha, T.V. \& Nayak, P.V. 2002. Electrodeposition of Zinc from Chloride Solution. Turkish Journal of Chemistry, 26, 725 - 733.

[48] Fayomi, O.S, Tau, V.R., Popoola, A.P.I, Durodola, B.M., Ajayi, O.O., Loto, C.A. \& Inegbenebor O.A. 2011. Influence of Plating Parameter and Surface Morphology on Mild Steel. Journal of Materials Environment Science, 2(3), 271-280. 
[49] Xia, X., Zhitomirsky, I., Mcdermid, J.R. 2009. Electrodeposition of Zinc and Composite Zinc-yttria Stabilized Zirconia Coatings. Journal of Materials Processing Technology 209, 2632-2640.

[50] FAYOMI, O.S.I, ABDULWAHAB, M. \& POPOOLA, A.P.I. 2013. Properties Evaluation of Ternary Surfactant-induced $\mathrm{Zn}-\mathrm{Ni}-\mathrm{Al}_{2} \mathrm{O}_{3}$ Films on Mild Steel by Electrolytic Chemical Deposition. Journal of Ovonic Research, 9(5), 123-132.

[51] Fayomi, O.S.I. And Popoola, A.P.I. 2015. Anti-Corrosion and Tribo-Mechanical Properties of Co-deposited $\mathrm{Zn}-\mathrm{SnO}_{2}$ Composite Coating. Acta Metallurgica Sinica (English Letters), 28, 521-530.

[52] Fayomi, O.S.I., Aigbodion, V.S. \& Popoola, A.P.I. 2015. Properties of TiC/TiB Modified Zn-TiC/TiB Ceramic Composite Coating on Mild Steel. Journal of Failure Analysis and Prevention, 15, 54-64.

[53] Malatji, N. \& Popoola, A.P.I. 2015. Electrodeposition of Ternary $\mathrm{Zn}-\mathrm{Cr}_{2} \mathrm{O}_{3}-\mathrm{SiO}_{2} \mathrm{Nano}-$ composite Coating on Mild Steel for Extended Applications. International Journal of Electrochemical Science, 10, 3988 - 4003.

[54] Praveen, B.M. \& Venkatesha, T.V. 2008. Electrodeposition and Properties of Zn-nanosized $\mathrm{TiO}_{2}$ Composite Coatings. Applied Surface Science, 254, 2418-2424.

[55] Sajjadnejad, M., Mozafari, A., Omidvar, H. \& Javanbakht, M. 2014. Preparation and Corrosion Resistance of Pulse Electrodeposited and Zn-SiC Nanocomposite Coatings. Applied Surface Science, 300, 1-7.

[56] Praveen, B.M. \& Venkatesha, T.V. 2009. Generation and Corrosion Behavior of ZnNano Sized Carbon Black Composite Coating. International Journal of Electrochemical Science, 4, 258-266.

[57] Malatji, N., Popoola, A.P.I., Fayomi, O.S.I. \& Loto, C.A. 2015. Multifaceted Incorporation of $\mathrm{Zn}-\mathrm{Al}_{2} \mathrm{O}_{3} / \mathrm{Cr}_{2} \mathrm{O}_{3} / \mathrm{SiO}_{2}$ Nanocomposite Coatings: Anti-corrosion, Tribological, and Thermal Stability. The International Journal of Advanced Manufacturing Technology, $1-7$.

[58] Borkar, T. 2010. Electrodeposition of Nickel Composite Coatings. M.Sc. dissertation, Oklahoma, Oklahoma State University.

[59] Yu, S.R., Liu, Y., Li, W., Liu, J.A. \& YUAN, D.S. 2012. The Running-in Tribological Behavior of $\mathrm{Nano}_{-} \mathrm{SiO}_{2} / \mathrm{Ni}$ Composite Coatings. Composites: Part B, 43, 1070-1076.

[60] Zheng, H. \& AN, M. 2008. Electrodeposition of $\mathrm{Zn}-\mathrm{Ni}-\mathrm{Al}_{2} \mathrm{O}_{3}$ Nanocomposite Coatings under Ultrasound Conditions. Journal of Alloy and Compounds, 459, 548-552.

[61] Ghaziof, S. \& Gao, W. 2015. The Effect of Pulse Electroplating on Zn-Ni Alloy and $\mathrm{Zn}-\mathrm{Ni}-\mathrm{Al}_{2} \mathrm{O}_{3}$ Composite Coatings. Journal of Alloys and Compounds, 622, 918-924. 